finger from the perineum indicates, by reason of the limited connections of the growth, the expediency of attempting its complete removal, or if the mass is considerable, the suprapubic incision may with adrantage be proceeded with. The value of the perineal incision for drainage has already been demonstrated in several instances of this kind. Still, on the whole, the less intravesical malignant growths are interfered with the better, so far as concerns both the comfort and life of the patient. Of the curable forms of intravesical tumour of the bladder, the simple papilloma or villous growth furnishes us with an example, and this has undoubtedly within the present lecade been brought within the reach of surgery. In the cases of this kind where I have operated, I have been able to accomplish all that I desired by a perineal incision. The following instances illustrate some of the difficulties connected with the diagnosis and treatment of tumours of the bladder. The first was that of a young man I saw in 1883 , who was suffering from hæmaturia. I opened his bladder from the perineum, and removed a villous growth, which seemed to occupy the orifice of the left ureter; he was temporarily relieved, but in the course of a month he died of exhaustion in consequence of repeated attacks of hæmaturia. After death, the left ureter was found dilated; the pelvis of the left kidney was olso dilated, and contained a villous growth resembling that which I had removed from the blaclder.

The other cuse was that of a middle-aged man, who presented all the symptoms of calculous pyelitis of the left kidney. The pain was so severe that I determined to open and explore the kidney, which I did in the early part of December, 1887. I found the kidney not much larger than natural, but it was simply $n$ bag of pus. I could find no stone or other cause for the renal obstruction. The bladder was examined, but nothing abnormal was detected. The patient had a good deal of hrematuria after the ojeration. He got gradually weaker, and died about four weeks nfter the operation. At a post-mortem examination, a small epithelioma of the bladder was found, which had completely occluded the left ureter, and had thus led to the disorganisation of the corresponding kidney. Such are illustrations of some of the difficulties which attend the diagnosis of tumours connected with the interior of the bladder; they certainly seem to indicate the great eaution that is necessary in coming to a conclusion that their extirpation should be attempted.

1 have now completed the task which you, in your kindness, have imposed upon me. It only remains for me to thank you for the patient and attentive hearing you have given me.

\section{A CASE OF CIRRHOSIS OF THE LIVER,}

WITI CHRONIC CEREBRAL SYMPTOMS DEPENDING UPON THE

CIRCULATION IN TIIE BIOOD OF DIGESTIVE IMPURITIES.1

Br DAVID DRUMMIOND, M.D.,

Physician to the Newcastle-on-Tyne Infirmary, etc.

1 HAVE ventured to invite the attention of the members interested in the Medicine Section for a few moments to a case which I confess puzzled me not a little when attempting to interpret its clinical features. In addition to throwing some light upon certain nervous phenomena that have given rise to difference of opinion from time to time-I refer to some of the nerrous symptoms of acute yellow atrophy of the liver, so-called bilious attacks, and allied conditions-it exemplifies the manner in which an organic lesion of one portion of the economy may be responsible for symptoms referable to another that practicaily inusk and wershadow those of the primary lesion; just as in winter the scion mistletoe may usurp the importance of the apple by concealing with its evergreen leaves the naked branches of the stock. 1 regret that the early history of the case I am about to relate is not as accurate as I could wish, owing to the fact that the patient's memory was considerably impaired, and in consequence we were dependent upon his wife, who lived at a distance, for the major portion of the details. It is also a matter of regret that some of the points were not more exhaustively worked up; but we are all wise after the event, and I suspect a post-mortem examination suggests to the minds of a good many of us errors of

\footnotetext{
1 Read in the Section of Medicine at the Annual Meeting of the British Med: cal Association, held at Dublin, August, 1887.
}

omission which good resolutions prompt us to aroid in the

future.

J. W., aged 39, a sailor, an American by birth, was ad. mitted into the Newcastle-on-Tyne Infirmary on September $9 t_{\text {, }}$ 1886. His previous history, as far as it could be ascertained, was as follows. For eighteen years he had sailed from English ports, and during that time he was much exposed to malarial influences, chiefly in New Orleans. There was no history of syphil:s or of alcoholic excesses. Nine years previously he had suffered from a severe attack of intermittent ferer, and some time later was admitted into Guy's IIospital for jaundice. On recovering he returned to sea, and remained in good health until the beginning of 1886, when he began to complain of weakness, loss of appetite, etc. He continued to perform his duty, though with difficulty, until February 2nd, when he was obliged to leave the ship on account of illness. On his return home his wife remarked that his skin was sallow, that he looked ill, and that his mental condition was altered. He was fitful, for example, and was inclined to wander about the streets in an nimless way, which he did for two or three days, when an attack of excitement with delirium occurred, and it was with difficulty his friends could restrain him in bed; indeed he occasionally eluded their vigilance, and rushed into the streets in his nightshirt. For some weeks this condition continued, though the excitement became more controllable, and his mental state gradually improved.

On March 30th (1886) he was admitted into the Middlesbrough Infirmary, having presented himself in the first instance as an out-patient for right inguinal hernia, when an enlargement of the spleen was detected. During his stay in the Middlesbrough Infirmary, which was for upwards of four months, his speech and sight were noticed to be impaired, and his mental condition peculiar; his memory was defective, and he was as a rule markedly apathetic, though occasionally emotional. The tendon jerk was increased in both arms and legs.

Whilst under treatment in hospital his general health improved, but his nervous symptoms remained unaltered. He then returned home for some weeks, when his wife found it very diffcult to manage him. Ile took a dislike to his children, and made free use of the most foul language. 2 practice that was foreign to him. He would lie for hours at a time taking no notice of the surroundings, and then break out into a state of wild excitement. Ile now rapidly became weaker, and at the same time more unmanagenble, so that his wife was glad to transfer him to the Newcastle Infirmary.

On admission he was observed to be a dark-complexioned man, fairly well nourished, with a peculiar earthy sallow pallor of the skin, and looked older than his age. His speech was slow, drawling, and deliberate, and strongly suggested the speech of a general paralytic. His memory was decidedly weakened, though at times he appeared to have accurate glimpses of his past life. He was highly emotional, laughing or crying easily. The sclerotics were tinged yellow. The tongue was clean and was protruded tremulously; there was, however, no tremor of the lips. The arme shook on muscular exertion, as, for example, when he lifted a cup to his mouth. A similar tremor affected the head on sitting or standing. The gait was unsteady, swaying, and tremulous. The tendon-jerk phenomenon was decidedly increased in both upper and lower extremities. The plantar reflex was absent. The limbs were much stronger on the right side than the left; in fact, there seemed to be a slight degree of left-sided hemiplegia. There was no annsthesia, but, on the contrary, a certain degree of general hyperasthesia was remarked. The spleen was considerably enlarged, rounded, and firm, and reached to the level of the umbilicus and to within an inch of the middle line. The liver dulness was diminished. The urine was passed in considerable quantities, the daily amount being rather above the average, varying from 50 to 80 ounces in the twenty-four hours. It was the colour of Madeira, bright and clear, and contained more than a trace of bile, but no albumen or sugar. ${ }^{2}$ Several specimens were sent to Dr. Bedson, the Professor of Chemistry in the College of Physical Science, who was asked to examine it for iron, and lie kindly furnished me with the following report :

"Several determinations of the iron in the first sample of urine received in December, 1886, were made, and the most reliable give 38 milligrammes of iron per litre. I had some trouble with this sample, some of the iron determinntions appearing excessively high. The second sample was examined two weeks later, and

${ }^{2}$ The test for sugar was only made once by the clictlcal assistant, anit his 2 The test for sugar was
observation was not veritied. 
found to contain 39.6 milligrammes of iron per litre; this sample was examined for bile, and found to contain bile acids. The third sample was received on December 23rd, and was found to contain 10.34 milligrammes of iron per litre. These amounts, expressed in grains per ounce are as follows:

1. -0.016 grains of iron per ounce.

III. -0.0045

"No. III represents, it would appear, the" normal amount of iron found in the ash of urine, whilst in Cases I and II the amounts are between three and four times this quantity."

An examination of the blood showed a diminution in the number of red corpuscles; some appeared to be crescent-shaped, and many were below the average in size. In a cubic millimètre there were $3,460,000$ red and 6,600 white, or about 1 white to 520 red corpuscles. There were no changes detected with the ophthalmoscope. For some weeks little or no alterntion was apparent in his condition. He took food fairly well, and the bowels were opened regularly every day. The temperature and pulse maintained an even line of health, though as time wore on it was observed that the thermometer in the axilla seldom indicated more than $97.4^{\circ} \mathrm{F}$. in the morning. The nervous symptoms gradually increased. The speech became less distinct, more drawling, and syllabic; the sight appeared to grow more and more dim; muscular power diminished generally, and inco-ordination increased, so that he found it impossible to stand or walk alone. His mental obliquity became more decided, and occasional attncks of excitement varied an otherwise monotonous state of helpless -apnthy. The bilious colorntion of the skin developed slowly, and the urine became darker, though the aspect of the patient was more one of profound angemia than jaundice.

The note on February 12th, 1887-five months after his admission to hospital, and some time after the diagnosis of cirrhosis of the liver was definitely made-is as follows:

Since last observation the patient has been going down the hill steadily: the speech is thicker, and even more suggestive of general paralysis. Is very drowsy, quiet, and inoffensive; the conjunctivæ are more deeply tinged. He trembles very much when he attempts to stand, and is quite unable to walk alone. No ascites. Liver dulness is reduced to one inch of dull area in the neighbourhood of the sixth interspace in the anterior axillary line. Well-marked systolic murmur in the tricuspid area. Temperature normal : pulse 70. Reflexes the same as before.

On February 24th the nurse reported that during the previous few days she had observed that the patient had become more irritable and excited. He was now delirious and wildly excited; the pupils were dilated and fixed; the tongue was dry and brown.

On February 26th, as the delirium still continued, one-sixtieth of a grain of hyoscyamine was injected hypodermically, but with very little effect. Next day, spasmodic attacks, chiefly of the muscles of the back, arms, and face, were observed. During a spasm the back was arched (opisthotonos), and the mouth was twisted to the right side, and in the interval between these attacks. choreiform movements of the head, trunk, and limbs, with marked horizontal nystagmus, occurred. The urine now contained a considerable quantity of blood, and coarse crepitations were audible in the lungs. These irregular choreiform movements, affecting chiefly the legs and fingers, continued until March 9th, when they subsided in great measure, and consciousness partially returned. The jaundice was now pronounced, and, rapidly becoming more and more prostrated, he died on March 16th, fifteen months from the date that was supposed to fix the origin of the symptoms.

Necropsy.- Rigor mortis pronounced; right leg cedematous; universal jaundice, though not of a deep tint.-I Ieart: Both ventricles dilated; the right contained $\mathrm{n}$ quantity of ante-mortem clot; aortic valves competent; mitral and tricuspid orifices dilated, their valves normal. Lungs: Right adherent; lower lobe congested and codematous; muco-pus exuded from the cut ends of the bronchial tubes; a number of patches of catarrhal pneumonia ; the left lung presented similar appearances. Abdomen : No effusion; a large tortuous vein, the size of the middle finger, ran in the course of the round ligament of the liver, and, passing on to the right side of the abdominal wall, it descended, covered by peritoneum, in the position of the deep epigastric vein, to join the right external iliac just above Poupart's ligament. On tracing this abnormal vein down the round ligament, it was seen to enter the left branch of the portal about an inch from the bifurcation; in fact, it was practically the direct continuation of the left division of this vein. The liver was small, granular, and decidedly cirrhotic. It weighed 40 ounces, and on section the substance was seen to be broken up into small yellow islands or nodules, varying in size from a pin's head to a split pea. The larger branches of the portal vein in the liver were filled with firm blood-clot (tlirombosis). The gall-bladder contained about. 2 ounces of thick, tar-like bile. The larger bile-ducts were not, obstructed. The spleen was enlarged, and weighed 39 ounces. It was soft and pale, and a section disclosed a large number of dilated veins. The trunk of the splenic vein was dilated to about twice its normal size. The kidneys were slightly enlarged, but. beyond a somewhat adherent capsule, presented nothing ahnormal. The hæmorrhoidal and œsophageal veins were much enlarged. The brain was pale, soft, and oedematous, but otherwise seemed quite healthy ; the membranes, grey matter, and vessels showed no morbid clianges.

The view taken of the case in the light of the post-mortem examination was that the cerebral symptoms resulted entirely from the poisonous effects of digestive impurities circulating in the brain. It was quite obvious that the portal blood entered almost directly into the systemic circulation, without passing through the liver, and therefore was not subjected to the purifying influences of that organ, but passed at once to the brain, whose functions were consequently disturbed. The occurrence of nervous symptoms in the course of a case of hepatic cirrhosis is no new observation, but as a rule they have intervened towards the end of the case, and I am not aware of any cases entirely parallel with the one I have just related, though Frerichs cites the case of a boy, aged 10, who, along with cirrhosis, suffered from difficulty of speech, paralysis of the facial muscles, and general muscular weakness, but without mental symptoms until shortly before death. He has observed, however, noisy deiirium with spasmodic muscular contractions; and Dr. Ililton Fagge refers to a man with cirrhosis who lay for two or three weeks in a semi-comatose condition.

The symptoms in my case resembled very closely those of a case of general paralysis. The attacks of excitement, the tendency to melancholic depression, the slow, drawling speech, and the muscular inco-ordination furnished a picture that could not fail to suggest that disease. On the other hand, the noisy delirium and extreme restlessness towards the termination of the case brought forcibly to one's mind the features of a case of acute yellow atrophy. The accessory portal vein running in the round ligament has been met with by Sappey, and Rindfleisch describes a case in which the portal blood passed directly into the cava through a number of dilated nnastomoses hetween the mesenteric and spermatic veins, but I am not aware that there is any record of the symptoms in these cases.

\section{ON ADDISON'S DISEASE AND THE FUNCTION OF THE SUPRARENAL BODIES.'}

Bт C. A. M.AC MUNV, M.A., M.D.Dub., Wolverhampton.

No satisfactory explanation has yet been given of th: bronzing of the skin and of the peculiar train of symptoms which frequently accompany disease of the suprarenal bodies, and this is not surprising since anatomists and physiologists can give us no idea as to the function of these organs.

In this paper I have collected certain bits of evidence which may help to alvance the inquiry a stage, even if $\mathrm{my}$ arguments should fail to convince the critienl.

I propose to consider the subject under the following heads: 1, the comparative anatomy and development of the airenals; 2 , their physiological chemistry; 3 , theories as to their function; 4, results of spectroscopic examination of the adrenals and of the urine in Addison's disease; and 5; tenchings of pathology.

Comparative Anatomy and Development of the Suprarenal. Bodies-The great use of the adrenuls in the life of animals is proved by their wide distribution among vertebrates: since the? are found in mammals, bircls, reptiles, amphibians, and fishes.

In fishes they lie on the anterior or posterior surface of the kidneys as small paired or multiple bodies, varying in size from that of a pin's head to that of a bean (Eberth). ${ }^{2}$ In elasmobranchs

1 Read before the Pathological Section of the Birningham Brauch of the British Merlical Association, January 27 th, 1888.

2 Stricker's Histology. 